\title{
Presence of Bacterial Virulence Gene Homologues in the dibenzo-p-dioxins degrading bacterium Sphingomonas wittichii
}

\begin{abstract}
Amr T. M. Saeb*
Biotechnology Department, Strategic Center for Diabetes Research, College of medicine, King Saud University, Saudi Arabia. Amr T. M. Saeb, E-mail: saeb.1@osu.edu; Corresponding author

Received May 29, 2016; Revised June 22, 2016; Accepted June 23, 2016; Published July 26, 2016

Abstract:

Sphingomonas wittichii, a close relative of the human pathogen Sphingomonas paucimobilis, is a microorganism of great interest to the bioremediation community for its ability of biodegradation to a large number of toxic polychlorinated dioxins. In the present study we investigated the presence of different virulence factors and genes in S. wittichii. We utilized phylogenetic, comparative genomics and bioinformatics analysis to investigate the potentiality of $S$. wittichii as a potential virulent pathogen. The 16SrDNA phylogenetic tree showed that the closest bacterial taxon to S. wittichii is Brucella followed by Helicobacter, Campylobacter, Pseudomonas then Legionella. Despite their close phylogenetic relationship, S. wittichii did not share any virulence factors with Helicobacter or Campylobacter. On the contrary, in spite of the phylogenetic divergence between S. wittichii and Pseudomonas spp., they shared many major virulence factors, such as, adherence, antiphagocytosis, Iron uptake, proteases and quorum sensing. S. wittichii contains several major virulence factors resembling Pseudomonas sp., Legionella sp., Brucella sp. and Bordetella sp. virulence factors. Similarity of virulence factors did not match phylogenetic relationships. These findings suggest horizontal gene transfer of virulence factors rather than sharing a common pathogenic ancestor. S. wittichii is a potential virulent bacterium. Another possibility is that reductive evolution process attenuated $S$. wittichii pathogenic capabilities. Thus plenty of care must be taken when using this bacterium in soil remediation purposes.
\end{abstract}

Keywords: Sphingomonas wittichii, Virulence factors, Phylogenetics, Comparative genomics, Bioinformatics, Pseudomonas sp.

\section{Abbreviations:}

GDLs: Glycosphingolipids; 16S rDNA: 16S ribosomal RNA; NJ: Neighbor-Joining; MCL: Maximum Composite Likelihood; taxid: Taxon identity; cAMP: Cyclic adenosine phosphate; HSF: Histamine sensitizing factor; LPF: Lymphocytosis promoting factor (LPF); IAP: Islet-activating protein.

\section{Background:}

Sphingomonas wittichii is a bacterium of immense importance in the context of bioremediation because of its ability to biodegrade large number of toxic polychlorinated dioxins and to utilize both non-chlorinated dibenzo-p-dioxin and non-chlorinated dibenzofuran as a growth substrate and a sole source of carbon and energy [1]. S. wittichii belongs to the genus Sphingomonas that is a group of Gram-negative, rod-shaped, non-sporeforming, chemoheterotrophic, strictly aerobic bacterium that produces yellow or off white pigmented colonies. The distinctive features of Sphingomonas include its possession of ubiquinone 10 as its

ISSN 0973-2063 (online) 0973-8894 (print) major respiratory quinone, the presence of glycosphingolipids (GDLs) in their cell envelopes and its metabolic versatility [2].

Members of the Sphingomonas genus are gaining popularity for their significant ability to degrade numerous recalcitrant compounds [3-6]. The completed 5,915,246-bp genome of $S$. wittichii consists of a main chromosome of 5,382,261 bp and two mega-plasmids, designated as pSWIT01 and pSWIT02 with sizes of $310,228 \mathrm{bp}$ and $222,757 \mathrm{bp}$ respectively [7]. S. wittichii is also known to be a compelling degrader of toxic dioxin pollutants, as it fully degrades the organic backbone of the dibenzo-p-dioxin structure $[6,8]$. This bacterium was largely isolated for its ability 
to grow on dioxin-like compounds as the sole carbon and energy source [6]. And since its isolation, compelling research has shown that $S$. wittichii can biodegrade a larger number and greater diversity of chlorinated diaryl ethers than any other known bacterium $[6,9,10]$.

In a previous study, we confirmed the presence of many virulence factors in S. paucimobilis, a human pathogen that had been frequently isolated from Diabetic foot ulcer patients [11] and is also closely related to $S$. wittichii. Henceforth, in this study, we aimed to investigate the pathogenic potentials of Sphingomonas wittichii by employing comparative genomics and bioinformatics techniques. This is the first study to investigate the presence of bacterial virulence factors in the presumed environmentally friendly bacterium, S. wittichii.

\section{Methodology:}

Phylogenetic relationships reconstruction:

We acquired partial 16S rDNA sequences of selected Sphingomonas species and pathogenic bacteria from the GenBank (Supporting information Table 3). These sequences were then aligned using the Bioedit built-in clustal $\mathrm{W}$ program (gap opening penalty $=10$, gap extension penalty $=5$, delay divergent sequences $=40 \%)$. We compared the resulting alignments and the final alignments were improved manually and prepared in FASTA, MEGA formats using format converter tool v2.2.5 available online at: http://www.hiv.lanl.gov/ content/sequence/FORMAT_CONV E RSION/form.html.

In order to establish the phylogenetic relationships among taxa, tree was constructed using the Maximum Likelihood (ML) method based on the Tamura-Nei model and Jukes Cantor the best fit to the data according to AIC criterion [12]. The percentage of trees in which the associated taxa clustered together is shown next to the branches. Initial tree(s) for the heuristic search were obtained automatically by applying Neighbor-Join and BioNJ algorithms to a matrix of pairwise distances estimated using the Maximum Composite Likelihood (MCL) approach, and then the topology was selected with superior log likelihood value. The tree was drawn to scale, with branch lengths measured in the number of substitutions per site. The analysis involved 18 nucleotide sequences. Codon positions included were 1st+2nd+3rd+Noncoding. All positions containing gaps and missing data were eliminated. MEGA6 (program/software/tool) was used to conduct evolutionary analyses and pairwise distance [13].

\section{Comparative genomics analysis:}

Virulence genes sequences and functions, corresponding to different major bacterial virulence factors of chosen pathogens, were acquired as described before by Saeb et al. [11]. Sequences were acquired from GenBank then compared and validated with virulence factors of pathogenic bacteria data base Supporting information Table 2 that shows the tested major pathogenic virulence factors. Selected gene sequences were tested against available Sphingomonas gene information using Sphingomonas Nucleotide BLAST tool. The search set all Sphingomonas complete genomes and selected organism was Sphingomonas (taxid: 13687). Because of evolutionary divergence of the tested and query taxa we used BLASTN that is optimized for fairly similar sequences.

Table 1: Major pathogenic taxa used in the comparative analysis against Sphingomonas wittichii

\begin{tabular}{llll}
\hline Genus & Species & Host & Disease \\
\hline Brucella & B. abortus & Human and Cattle & Brucellosis, Osteoarthritis, endocarditis and several neurological disorders \\
& B. canis & Human and Dogs & Brucellosis, Osteoarthritis, endocarditis and several neurological disorders \\
& B. melitensis & Human Goats and Sheep & Brucellosis, Osteoarthritis, endocarditis and several neurological disorders \\
& B. ovis & Sheep & Brucellosis, Osteoarthritis, endocarditis and several neurological disorders \\
Helicobacter & B. suis & Human and Pigs & Brucellosis, Osteoarthritis, endocarditis and several neurological disorders \\
& H. acinonychis & Humans and other mammals & Bacterial carcinogen, Gastroduodenal diseases \\
& H. hepaticus & Humans and other mammals & Bacterial carcinogen, Gastroduodenal diseases \\
Campylobacter & C. pylori & Humans and other mammals & Bacterial carcinogen, Gastroduodenal diseases \\
& C. jejuni & Humans & Bacterial gastroenteritis \\
Legionella & L. pneumophila & Humans & Guillain-Barre syndrome (GBS) \\
Pseudomonas & P. aeruginosa & Human & Legionnaires' Disease \\
& P. syringae & Plant & Eye, burn and wound infections \\
& & & Bacterial speck and bacterial blight
\end{tabular}

Table 2: Suggested Sphingomonas wittichii toxin information in relation to Bordetella pertussis toxins.

\begin{tabular}{|c|c|c|c|c|c|c|}
\hline \multirow{2}{*}{ Bordetella Toxin } & \multirow{2}{*}{$\begin{array}{c}\text { Related } \\
\text { Gene }\end{array}$} & \multirow{2}{*}{ Product name } & \multirow{2}{*}{ Genbank ID } & \multicolumn{3}{|c|}{ Shingomonas spp } \\
\hline & & & & E value & Identity (\%) & Accession \\
\hline Cya (Invasive & cyaA & bifunctional hemolysin-adenylate cyclase precursor & 33591934 & 2.00E-12 & 73 & NC_009511.1 \\
\hline Adenylate cyclase/ & cyaD & cyclolysin secretion protein & 33591936 & 8.00E-04 & 81 & NC_009511.1 \\
\hline haemolysin) & cyaE & cyclolysin secretion protein & 33591937 & 2.00E-04 & 89 & NC_009511.1 \\
\hline & ptlC & putative bacterial secretion system protein & 33594645 & $3.00 \mathrm{E}-06$ & 88 & NC_009511.1 \\
\hline Ptx (Pertussis toxin) & ptlF & putative bacterial secretion system protein & 33594649 & $5.00 \mathrm{E}-04$ & 76 & NC_009511.1 \\
\hline & ptlH & putative bacterial secretion system protein & 33594651 & 3.00E-08 & 75 & NC_009511.1 \\
\hline
\end{tabular}


Table 3: Comparative analysis Sphingomonas wittichii against major bacterial virulence factors and functions

\begin{tabular}{|c|c|c|c|c|c|c|}
\hline Bacterial Taxa & Major virulence factors (VFs) & Sub VFs & Related Gene & E value & Identity (\%) & Accession \# \\
\hline \multirow[t]{4}{*}{ Brucella } & \multirow{2}{*}{$\begin{array}{l}\text { Intra-cellular survival and Immuno- } \\
\text { modulatory activity }\end{array}$} & Mannose-1-phosphate guanylyl-transferase & $\operatorname{manC}$ & $3.0 \mathrm{E}-09$ & 77 & NC_009511.1 \\
\hline & & Phospho-glucomutase & $p g m$ & 0 & 74 & NC_009511.1 \\
\hline & \multirow[t]{2}{*}{ Secretion system } & VirB type IV & BMEII0026 & $6.0 \mathrm{E}-04$ & 90 & NC_020561.1 \\
\hline & & VirB type IV & BMEII0035 & $4.0 \mathrm{E}-06$ & 72 & NC_020561.1 \\
\hline \multirow{2}{*}{ Legionella } & Motility & Flagella & fliP & $1.0 \mathrm{E}-4$ & 66 & NC_009511.1 \\
\hline & Stress protein & SodB & $\operatorname{sod} B$ & $3.0 \mathrm{E}-04$ & 76 & NC_009511.1 \\
\hline \multirow[t]{65}{*}{ Pseudomonas } & \multirow[t]{17}{*}{ Adherence } & \multirow[t]{17}{*}{ Flagella } & fleQ & $4.0 \mathrm{E}-65$ & 72 & NC_009511.1 \\
\hline & & & $f \lg E$ & 5.0E-19 & 67 & NC_009511.1 \\
\hline & & & $\operatorname{flg} F$ & $7.0 \mathrm{E}-14$ & 71 & NC_009511.1 \\
\hline & & & $f \lg G$ & $3.0 \mathrm{E}-44$ & 68 & NC_009511.1 \\
\hline & & & $\mathrm{flg} H$ & 3.0E-25 & 72 & NC_009511.1 \\
\hline & & & flgI & $6.0 \mathrm{E}-87$ & 68 & NC_009511.1 \\
\hline & & & flgK & $1.0 \mathrm{E}-04$ & 94 & NC_009511.1 \\
\hline & & & flh $A$ & 2.0E-139 & 70 & NC_009511.1 \\
\hline & & & $\operatorname{flh} B$ & $2.0 \mathrm{E}-11$ & 70 & NC_009511.1 \\
\hline & & & $\operatorname{flh} F$ & $6.0 \mathrm{E}-05$ & 89 & NC_020561.1 \\
\hline & & & fliC & $1.0 \mathrm{E}-32$ & 72 & NC_009511.1 \\
\hline & & & $f l i E$ & $6.0 \mathrm{E}-04$ & 74 & NC_020561.1 \\
\hline & & & fliF & $3.0 \mathrm{E}-04$ & 66 & NC_020561.1 \\
\hline & & & fliN & $3.0 \mathrm{E}-16$ & 70 & NC_009511.1 \\
\hline & & & $f l i P$ & $7.0 \mathrm{E}-84$ & 72 & NC_009511.1 \\
\hline & & & fliQ & $2.0 \mathrm{E}-08$ & 84 & NC_020561.1 \\
\hline & & & fliR & $7.0 \mathrm{E}-08$ & 72 & NC_020561.1 \\
\hline & Adherence & LPS (lipopolysaccharide) & waaG & $4.0 \mathrm{E}-07$ & 76 & NC_020561.1 \\
\hline & & & waaP & $1.0 \mathrm{E}-04$ & 83 & NC_020561.1 \\
\hline & & Type IV pili & $\operatorname{chp} A$ & $2.0 \mathrm{E}-13$ & 69 & NC_009511.1 \\
\hline & & & $\operatorname{chpC}$ & 8.0E-05 & 82 & NC_020561.1 \\
\hline & & & fimU & $3.0 \mathrm{E}-04$ & 93 & NC_009511.1 \\
\hline & & & pilB & $3.0 \mathrm{E}-04$ & 93 & NC_009511.1 \\
\hline & & & pilG & $2.0 \mathrm{E}-04$ & 79 & NC_009511.1 \\
\hline & & & pilH & $2.0 \mathrm{E}-04$ & 77 & NC_009511.1 \\
\hline & & & pilJ & 2.0E-19 & 76 & NC_009511.1 \\
\hline & & & pilK & $3.0 \mathrm{E}-06$ & 83 & NC_020561.1 \\
\hline & & & pilQ & 1.0E-09 & 73 & NC_009511.1 \\
\hline & & & pilR & $9.0 \mathrm{E}-54$ & 70 & NC_009511.1 \\
\hline & & & pils & $2.0 \mathrm{E}-05$ & 74 & NC_009511.1 \\
\hline & & & pilT & $1.0 \mathrm{E}-07$ & 83 & NC_009511.1 \\
\hline & & & pilU & $1.0 \mathrm{E}-12$ & 75 & NC_009511.1 \\
\hline & & & $\operatorname{alg} A$ & $1.0 \mathrm{E}-21$ & 65 & NC_009511.1 \\
\hline & & & $\operatorname{alg} B$ & $2.0 \mathrm{E}-36$ & 69 & NC_009511.1 \\
\hline & & & algI & $1.0 \mathrm{E}-59$ & 67 & NC_009511.1 \\
\hline & & & algJ & 7.0E-04 & 94 & NC_009511.1 \\
\hline & & & alg $P$ & $1.0 \mathrm{E}-07$ & 80 & СР006644.1 \\
\hline & Biosurfactant & Rhamnolipid & rhlA & $5.0 \mathrm{E}-04$ & 89 & NC_009511.1 \\
\hline & Iron uptake & Pyochelin & $f p t A$ & $6.0 \mathrm{E}-08$ & 86 & NC_009511.1 \\
\hline & & & pchA & $8.0 \mathrm{E}-04$ & 93 & NC_009511.1 \\
\hline & & & $p \operatorname{ch} B$ & $6.0 \mathrm{E}-04$ & 67 & NC_020561.1 \\
\hline & & & $p c h C$ & $1.0 \mathrm{E}-04$ & 80 & NC_009511.1 \\
\hline & & & $p \operatorname{ch} D$ & 1.0E-09 & 67 & NC_009511.1 \\
\hline & & & $p c h E$ & $6.0 \mathrm{E}-05$ & 81 & NC_009511.1 \\
\hline & & & $p \operatorname{ch} F$ & $1.0 \mathrm{E}-07$ & 85 & NC_009511.1 \\
\hline & & & $p \operatorname{ch} G$ & $1.0 \mathrm{E}-05$ & 79 & NC_009511.1 \\
\hline & & & $p c h H$ & $4.0 \mathrm{E}-09$ & 67 & NC_009511.1 \\
\hline & & & pchI & $6.0 \mathrm{E}-13$ & 74 & NC_009511.1 \\
\hline & & Pyoverdine & $f p v A$ & 3.0E-12 & 68 & NC_020561.1 \\
\hline & & & pvdA & $8.0 \mathrm{E}-04$ & 86 & NC_009511.1 \\
\hline & & & $p v d D$ & $1.0 \mathrm{E}-04$ & 91 & NC_020561.1 \\
\hline & & & $p v d E$ & 7.0E-06 & 82 & NC_009511.1 \\
\hline & Pigment & Pyocyanin & phzM & $5.0 \mathrm{E}-05$ & 77 & NC_009511.1 \\
\hline & & Pyocyanin & phzS & $6.0 \mathrm{E}-05$ & 68 & NC_009511.1 \\
\hline & Protease & Alkaline protease & aprA & $5.0 \mathrm{E}-07$ & 76 & NC_009511.1 \\
\hline & & LasA & $\operatorname{las} A$ & $7.0 \mathrm{E}-04$ & 86 & NC_009511.1 \\
\hline & Regulation & Quorum sensing & rhlL & $3.0 \mathrm{E}-04$ & 93 & NC_009511.1 \\
\hline & Secretion system & xсp secretion system & $r h l R$ & $5.0 \mathrm{E}-09$ & 72 & NC_009511.1 \\
\hline & & & $x c p Q$ & $2.0 \mathrm{E}-46$ & 70 & NC_009511.1 \\
\hline & & & $x c p R$ & 3.0E-174 & 72 & NC_009511.1 \\
\hline & & & $x c p S$ & $1.0 \mathrm{E}-44$ & 66 & NC_009511.1 \\
\hline & & & $x c p T$ & $3.0 \mathrm{E}-23$ & 69 & NC_009511.1 \\
\hline & & & $x с p U$ & $2.0 \mathrm{E}-07$ & 78 & NC_020561.1 \\
\hline & & & $x c p W$ & $4.0 \mathrm{E}-04$ & 73 & NC_009511.1 \\
\hline & & & $x c p X$ & $6.0 \mathrm{E}-04$ & 88 & NC_009511.1 \\
\hline
\end{tabular}

ISSN 0973-2063 (online) 0973-8894 (print)
BIOMEDICAL 


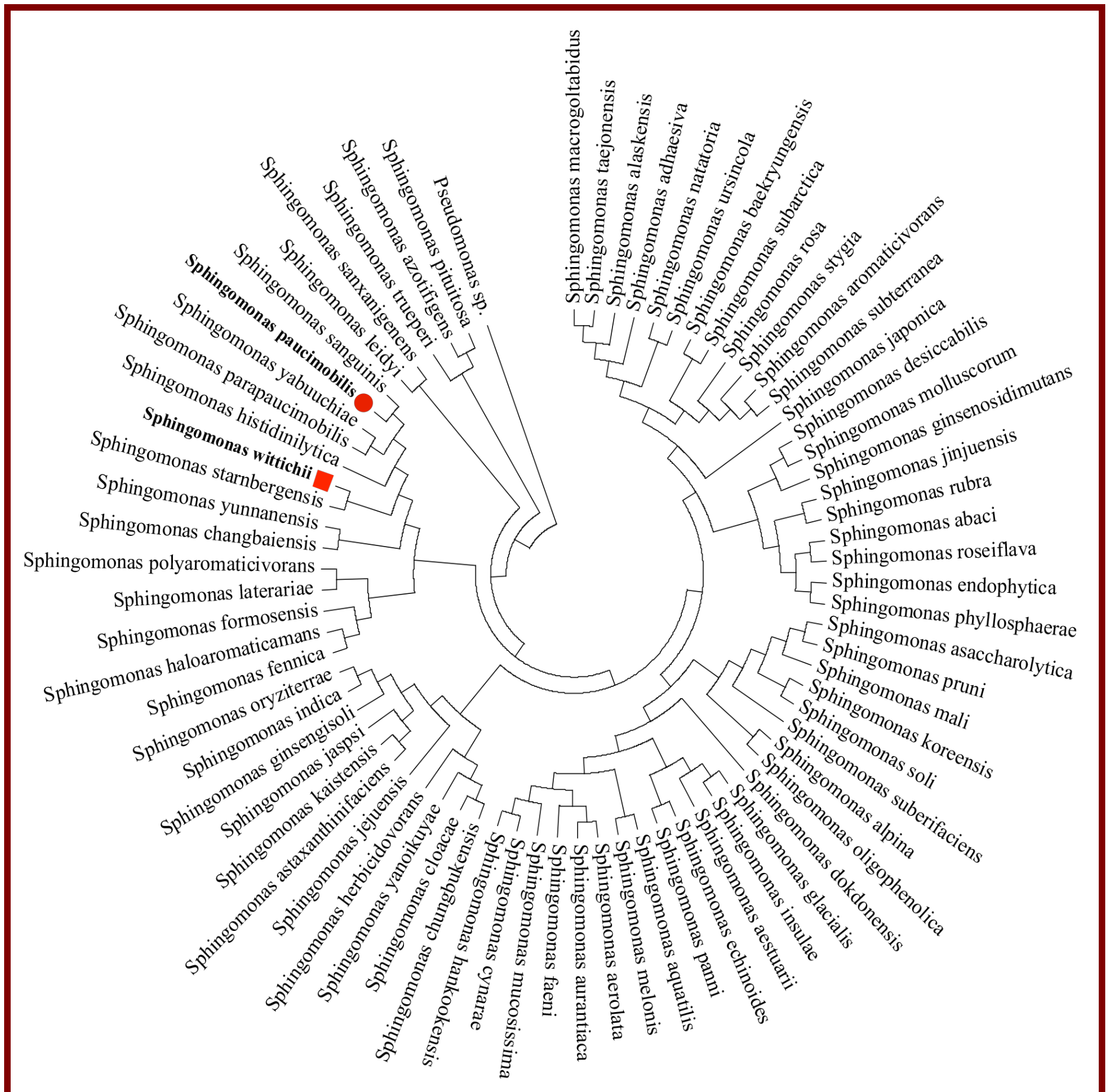

Figure 1: Partial 16SrDNA based phylogenetic tree for 74 species of genus Sphingomonas including the human pathogen S. paucimobilis.

\section{Results and Discussion:}

In this study, the presence of major known bacterial virulence factors in Sphingomonas wittichii was investigated. Phylogenetic relationships among 74 species of genus Sphingomonas, including the human pathogen Sphingomonas paucimobilis were reconstructed. Figure 1 shows the Partial 16SrDNA based Maximum Likelihood phylogenetic tree for all 74 species of the ISSN 0973-2063 (online) 0973-8894 (print) genus Sphingomonas. This figure also shows that Sphingomonas wittichii is a relatively close taxon to $S$. starnbergensis, $S$. histidinilytica, S. parapaucimobilis, S. yabuuchiae and the human pathogen $S$. paucimobilis. The pair wise genetic distance analysis was performed which showed the overall value of distance analysis among Sphingomonas species to be 0.05 . The individual values of pairwise distance between of $S$. wittichii with $S$. 
sanguinis, S. histidinilytica, S. parapaucimobilis, S. paucimobilis, S. yabuuchiae and the distantly related species $S$. mali were 0.016 , $0.026,0.048,0.042,0.042$ and 0.06 (Supporting information Table 1) respectively. The $S$. starnbergensis is a novel type of freshwater bacterium isolated from the prealpine mesotrophic Starnberger See (Bavaria, southern Germany). This species showed $95.3 \%$ sequence similarity with $S$. paucimobilis DSM 1098(T), the type species of the genus Sphingomonas [14]. While, the $S$. histidinilytica was isolated from an open hexachlorocyclohexane $(\mathrm{HCH})$ dump site at Ummari village in Lucknow, India. It showed 16S rDNA similarity of $99.4 \%$, with Sphingomonas wittichii DSM 6014(T) [15]. Moreover, S. yabuuchiae was identified from samples taken from the Russian space laboratory Mir. As shown in our results (Figure 1), S. yabuuchiae 16S rDNA sequence formed a coherent cluster with Sphingomonas sanguinis, Sphingomonas parapaucimobilis, Sphingomonas paucimobilis and Sphingomonas roseiflava with sequence similarity of $97 \cdot 5-98 \cdot 6 \%$ [16]. Sphingomonas wittichii also came in a coherent cluster with $S$. parapaucimobilis and $S$. paucimobilis, the only two species that are considered of human clinical significance [17].
The Maximum Likelihood method was used to construct a phylogenetic tree using partial 16S rDNA sequences of selected pathogenic bacteria as mentioned above in (Figure 2) and this was specifically done in order to make a guided decision for the choice of pathogenic bacteria species that will be used in the following comparative genomics analysis with Sphingomonas wittichii. This phylogenetic tree showed that Brucella sp. was the closest bacterial taxon to Sphingomonas, followed by Helicobacter spp., Campylobacter sp., Pseudomonas sp., and then Legionella sp. Based on these suggested phylogenetic relationships, the following bacterial species, Brucella sp., Helicobacter sp., Campylobacter sp., Pseudomonas sp. and Legionella $s p$, were selected for further comparative genomic and bioinformatics analysis.

Table 1 shows the selected bacterial genera with its corresponding species, hosts, and the diseases. All the chosen pathogens were mainly human, animal, protozoa, and plants pathogens. (Table 2) shows the virulent factors acquired by the chosen pathogens that were tested for its presence in S. wittichii genomic information. The major categories of bacterial virulence factors include adherence, endotoxin production, adherence, mobility, secretion systems and quorum sensing.

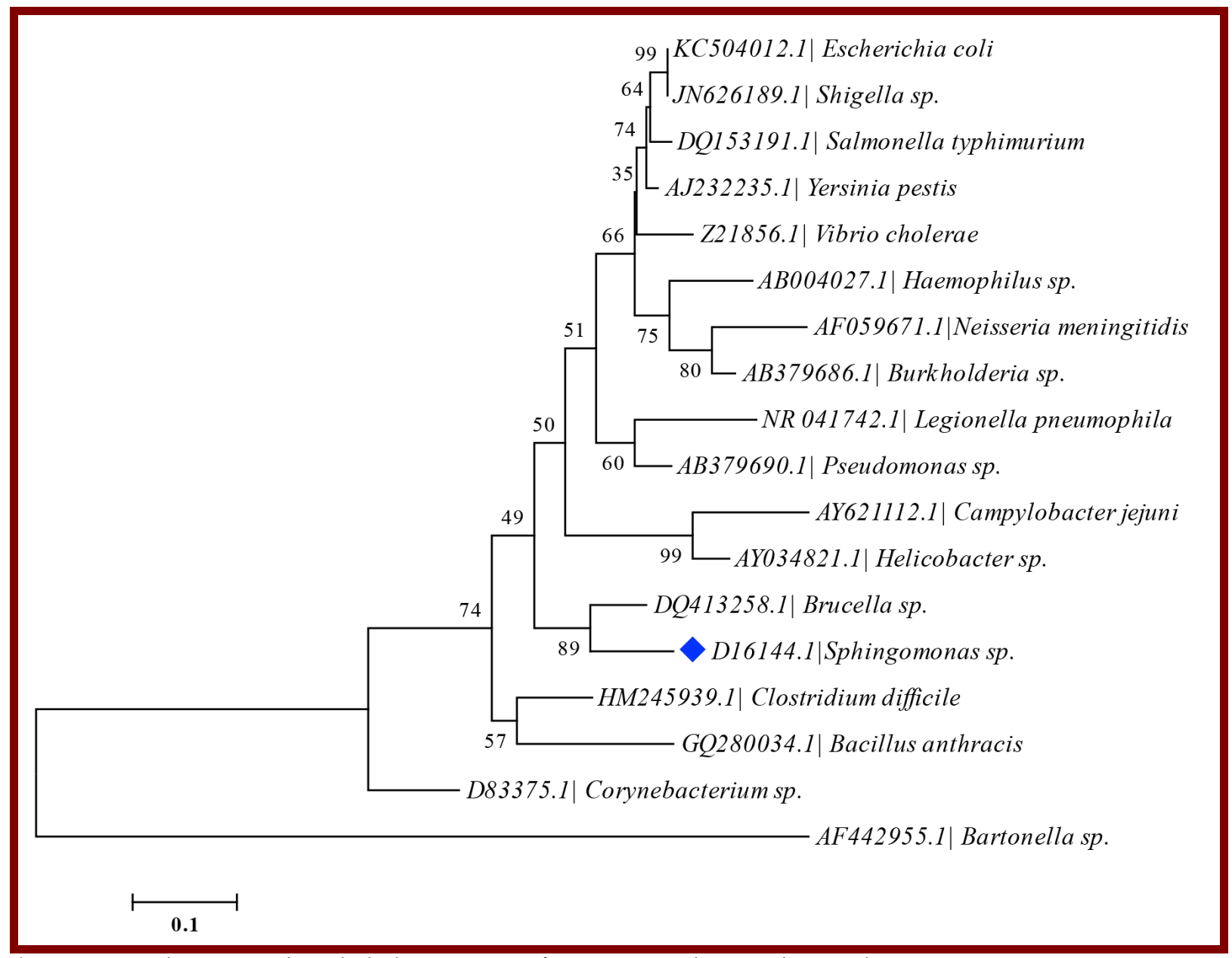

Figure 2: Partial 16SrDNA based phylogenetic tree for a major pathogenic bacterial taxa.

ISSN 0973-2063 (online) 0973-8894 (print) 
Table 3 and Figure 3 presents the shared virulence factors among S. wittichii and the selected five bacterial pathogens. Results in Table 3 showed that $S$. wittichii shares the genes accountable for intracellular survival capability (manC and pgm) with Brucella sp. with e-values ranging from 0 to 3.00E-09 [11-13]. In addition, Sphingomonas spp., shares the genes encoding for Type IV secretion system such as BMEII0026 with Brucella sp. with e-value of $6.00 \mathrm{E}-04$ and identity similarity of $90 \%$. On the contrary, $S$. wittichii does not share any virulence factors with Helicobacter spp. or Campylobacter sp. despite their close phylogenetic relationship. Moreover, S. wittichii shared Legionella $s p$. genes accountable for adherence and motility, namely, htpB and flip. In addition, $S$. wittichii and Legionella $s p$. shared the gene responsible for stress tolerance and sodB. The sodB encodes for superoxide dismutase which is a cytoplasmic iron superoxide dismutase important for intracellular survival and transmission [18].

Notwithstanding of the phylogenetic divergence between $S$. wittichii and Pseudomonas sp., it was noticed that they share several major virulence factors such as, adherence, antiphagocytosis, iron uptake, proteases, quorum sensing. $S$. wittichii and Pseudomonas sp. shared 19 genes of flagella formation (adherence) including flgK with e-value of 1.00E-04 and identity similarity of $94 \%$ and flgF with e-value of $6.00 \mathrm{E}-05$ and identity similarity of $89 \%$. The Flagella formation plays an important role as a virulence factor that enable motility toward the infection site, biofilm formation and several other pathogenic adaptations [1923]. Moreover, S. wittichii and Pseudomonas sp. shared many genes implicated in type IV pili biogenesis and mechanical function of pili, such as fimU with e-value of 3.00E-04 and pilB with e-value of 3.00E-04 and 93\% identity similarity. The type IV pili system plays an important role in adherence by assisting the pathogens to attach with their host cells and the twitching motility that allows the bacteria to move along the cell surface and in biofilm formation [20, 24-28]. Moreover, they shared two genes waaG and waaP implicated in lipopolysaccharide production that also play role in adherence ability. Additionally, S. wittichii and Pseudomonas $s p$. share many genes implicated in antiphagocytosis through alginate production. They shared six alginate genes including algJ with e-value of 7.00E-04 and identity similarity of $94 \%$ and alg44 with e-value of 7.00E-04 and identity similarity of $85 \%$. Alginate production allows pathogens to form bacterial biofilms and contributes to the persistence of bacteria in the lung by acting as an adhesin, which prevents the bacteria from being expelled from the infection site. The alginate slime layer makes it more difficult for phagocytes to ingest and kill the bacteria [2933].

Another important bacterial virulence factor shared between $S$. wittichii and Pseudomonas sp. is quorum-sensing ability. S. wittichii has both rhlL and rhlR with e-values of 3.00E-4 and 5.00E-9, respectively. Thus $S$. wittichii possess only rhl system of quorum sensing. Whilst in Pseudomonas sp. quorum sensing consists of two separate but interrelated systems, namely; las and rhl which are found to regulate the production of multiple virulence factors and are also crucial for proper biofilm formation [34-36]. In addition, S. wittichii and Pseudomonas sp. share seven genes encoding for $\mathrm{xcp}$ secretion system (Type II secretion system) including $x c p X$ and $x c p R$ with e-values of $1.00 \mathrm{E}-5$ and 3.00E-174, respectively. The xcp secretion system is found to be responsible for secretion of toxins and enzymes into the extracellular fluid $[37,38]$. It was also observed that both $S$. wittichii and Pseudomonas sp. share several genes involved in Iron uptake using both Pyochelin (10 genes) and Pyoverdine (4 genes). The Pyochelin is effective at enhancing iron uptake in $P$. aeruginosa, catalyzes the formation of tissue-damaging free radicals and also binds other transition metals (e.g. Mo (IV), Co (II)) with appreciable affinity and is also implicated in the delivery of both Co (II) and Mo (IV) to P. aeruginosa cells [39, 40]. The Pyoverdine is effective at acquiring iron from Transferrin and Lactoferrin. Moreover, Pyoverdine is cytotoxic due to its ability to stimulate the production of reactive oxygen species $[41,42]$.

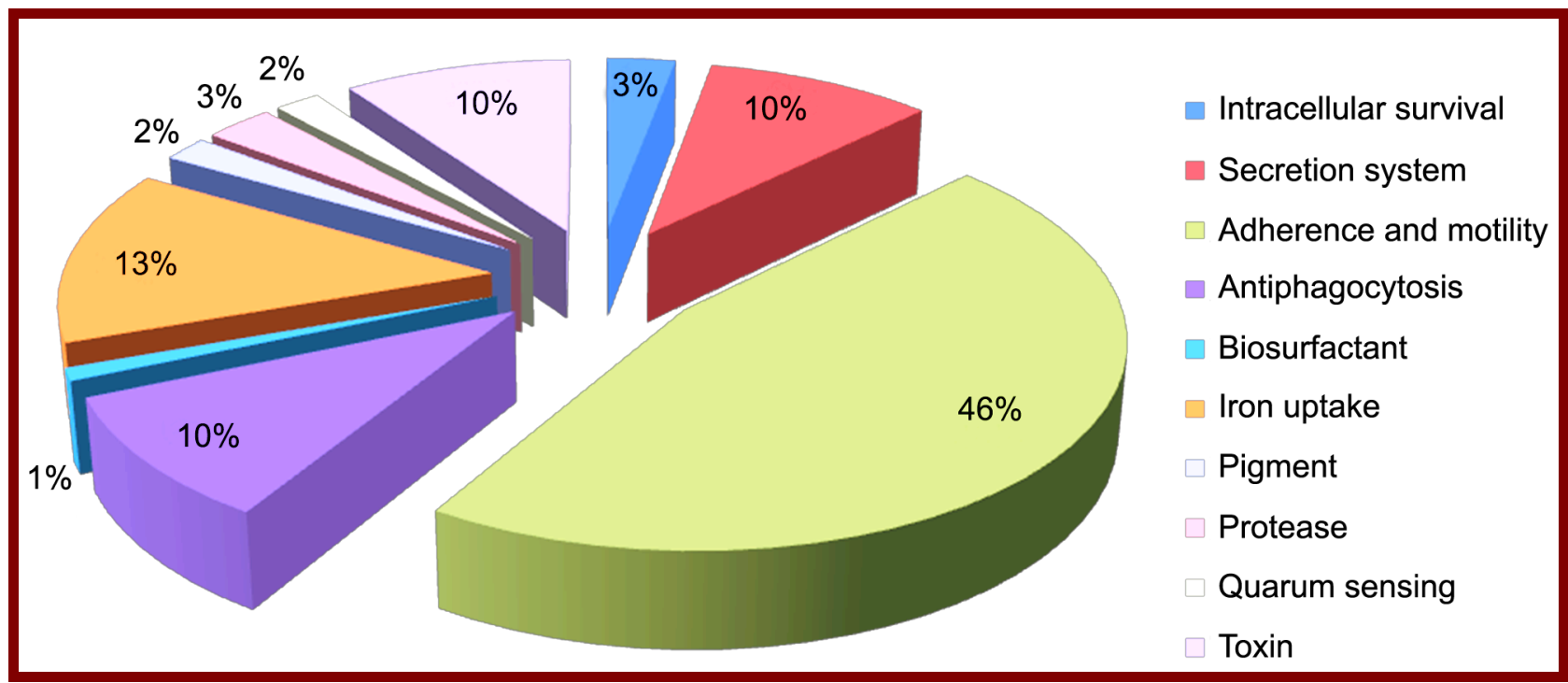

Figure 3: Percentage of different virulence factors associated with Sphingomonas spp.

ISSN 0973-2063 (online) 0973-8894 (print) 
Since production of bacterial toxins is very important aspect of virulence, we extended our comparative analysis in order to investigate the presence of toxin related genes in $S$. wittichii. Table 2 shows toxins that were found to share between $S$. wittichii and Bordetella pertussis, the strictly aerobic Gram-negative coccobacilli pathogen. B. pertussis is a strict human pathogen causing whooping cough, a highly contagious respiratory disease marked by severe, spasmodic coughing episodes [43-45]. It was also observed that $S$. wittichii contains genes for Invasive Adenylate cyclase /haemolysin, cyclolysin secretion protein which is a bi-functional toxin harboring both adenylate cyclase and hemolytic activities and functions primarily as an antiinflammatory factor [46-48]. Moreover, Sphingomonas spp. contains genes responsible for Pertussis toxin and its secretion system which assists in the attachment of B. pertussis to ciliated respiratory cells, important immunogen and activate cyclic Adenosine Phosphate (cAMP), Histamine Sensitising Factor (HSF), Lymphocytosis Promoting Factor (LPF), Islet-activating protein (IAP), interferes with leucocyte function and is haemolytic [49-53].

Results of this study showed that S. wittichii contains several major virulence factors mainly resembling Pseudomonas sp. Other virulence factors from Legionella sp., Brucella sp. and Bordetella sp., have also been observed. Moreover, the similarity of virulence factors did not correspond to the phylogenetic relationships. These findings suggest horizontal gene transfer of virulence factors rather than sharing a common pathogenic ancestor. The other possible scenario is that $S$. wittichii went through a reductive evolution process that attenuated its pathogenic capabilities. In both cases we suggest that lots of care must be taken when releasing $S$. wittichii higher concentrations in the process environmental remediation.

\section{Acknowledgments:}

We like to thank all members of the Information Technology Department in Strategic Center for Diabetes Research, College of Medicine, King Saud University

\section{References:}

[1] Halden RU et al. Appl Environ Microbiol. 1999 65:2246. [PMID: 10224029]

[2] Gai Z et al. Appl Environ Microbiol. 2007 73: 2832. [PMID: 17337542]

[3] Gai Z et al. Microbiol Read Engl. 2008 154: 3804. [PMID: 19047748]

[4] Stolz A. Appl Microbiol Biotechnol. 2009 81: 793.[PMID: 19002456]

[5] Wittich RM et al. Appl Environ Microbiol. 1992 58: 1005. [PMID: 1575472]

[6] Arellano-Reynoso B et al. Nat Immunol. 2005 6: 618. [PMID: 15880113]

[7] Miller TR et al. J Bacteriol. 2010 192: 6101. [PMID: 20833805]

[8] Wilkes H et al. Appl Environ Microbiol. 1996 62: 367. [PMID: 16535225]

[9] Halden RU et al. Appl Environ Microbiol. 2005 71:2442. [PMID: 15870332]
[10] Hong H-B et al. Appl Environ Microbiol. 2002 68: 2584. [PMID: 11976140]

[11] Saeb ATM et al. Evol Bioinforma. 2014 10: 229. [PMID: 25574122]

[12] Tamura K \& Nei M. Mol Biol Evol. 1993 10: 512. [PMID: 8336541]

[13] Tamura K et al. Mol Biol Evol. 2013 30: 2725. [PMID: 24132122]

[14] Chen H et al. Int J Syst Evol Microbiol. 2013 63: 1017. [PMID: 22685105]

[15] Nigam A et al. Int J Syst Evol Microbiol. 2010 60: 1038. [PMID: 19666786]

[16] Li Y et al. Int J Syst Evol Microbiol. 2004 54: 819. [PMID: 15143030]

[17] Toh HS et al. J Microbiol Immunol Infect. 2011 44: 289. [PMID: 21524965]

[18] Guidolin LS et al. J Bacteriol. 2009 191: 1230. [PMID: 19074375]

[19] Cardoso PG et al. Microb Cell Factories. 2006 5: 13. [PMID: 17090431]

[20] Haag AF et al. Int J Microbiol. 2010 2010: 124509. [PMID: 21151694]

[21] Sadosky AB et al. J Bacteriol. 1994 176: 3790. [PMID: 8206858]

[22] Feldman M et al. Infect Immun. 1998 66: 43. [PMID: 9423837]

[23] O’Toole GA \& Kolter R. Mol Microbiol. 1998 30: 295. [PMID: 9791175]

[24] Ciacci-Woolwine F et al. Infect Immun. 1999 67: 5176. [PMID: 10496893]

[25] Adamo R et al. Am J Respir Cell Mol Biol. 2004 30: 627. [PMID: 14607814]

[26] Dasgupta N et al. Mol Microbiol. 2003 50: 809. [PMID: 14617143]

[27] Hahn HP. Gene 1997 192: 99. [PMID: 9224879]

[28] Keizer DW et al. J Biol Chem. 2001 276: 24186 [PMID: 11294863]

[29] Skerker JM \& Berg HC. 2001 98: 6901. [PMID: 11381130]

[30] Mattick JS. Annu Rev Microbiol. 2002 56: 289. [PMID: 12142488]

[31] Whitchurch CB et al. Mol Microbiol. 2004 52: 873. [PMID: 15101991]

[32] Pier GB et al. Infect Immun. 2001 69: 1895. [PMID: 11179370]

[33] Nivens DE et al. J Bacteriol. 2001 183: 1047. [PMID: 11208804]

[34] Song Z et al. J Med Microbiol. 2003 52: 731.[PMID: 12909647]

[35] Stapper AP et al. J Med Microbiol. 2004 53:679.[PMID: 15184541]

[36] Franklin MJ, Douthit SA, McClure MA. J Bacteriol 2004 186: 4759. [PMID: 15231808]

[37] Miller MB \& Bassler BL. Annu Rev Microbiol 2001 55: 165. [PMID: 11544353]

[38] Erickson DL et al. Infect Immun 2002 70: 1783. [PMID: 11895939] 
[39] Smith RS \& Iglewski BH. P. CurrOpinMicrobiol 2003 6: 56. [PMID: 14617745]

[40] Chapon-Hervé V et al. Mol Microbiol. 1997 24: 1169. [PMID: 9218766]

[41] Filloux A et al. FEMS Microbiol Rev 1998 22: 177.[PMID: 9818381]

[42] Ankenbauer RG \&Quan HN. J Bacteriol 1994 176: 307. [PMID: 8288523]

[43] Poole K \& McKay GA. Front Biosci J Virtual Libr 2003 8: d66. [PMID: 12700066]

[44] Meyer JM et al. Infect Immun. 1996 64: 518. [ PMID: 8550201]

[45] Xiao R \& Kisaalita WS. Microbiol Read Engl 1997143 ( Pt 7): 2509. [PMID: 9245831]

[46] Terada LS et al. Infect Immun. 1999 67: 2371. [PMID:10225897]

[47] Luberto C et al. J Biol Chem 2003 278: 32733. [PMID: 12799377]

[48] Parkhill J et al. Nat Genet 2003 35: 32. [PMID: 12910271]
[49] Glaser P et al. EMBO J 1988 7: 3997. [PMID: 2905265]

[50] Gallay J et al. Eur J Biochem FEBS 2004 271: 821.[ PMID: 14764099]

[51] Bumba L et al. PLoSPathog. 2010 6: e1000901. [PMID: 2048556]

[52] Smith AM et al. FEMS Microbiol Rev. 2001 25: 309. [PMID: 11348687]

[53] Locht C et al. N. FEBS J 2011 278: 4668. [PMID: 21740523]

Edited by P Kangueane Citation: Saeb, Bioinformation 12(4): 241-248 (2016) License statement: This is an Open Access article which permits unrestricted use, distribution, and reproduction in any medium, provided the original work is properly credited. This is distributed under the terms of the Creative Commons Attribution License. 